\title{
O QUE O REFERENCIAL CURRICULAR NACIONAL PARA EDUCAÇÃO INFANTIL ESCLARECE SOBRE A EDUCAÇÃO MUSICAL NO CONTEXTO ESCOLAR?
}

\author{
Everton Tomiazzi ${ }^{1}$, Luciana Carolina Fernandes de Faria ${ }^{2}$, Raquel Rosan Christino Gitahy ${ }^{3}$ \\ ${ }^{1}$ Discente do Mestrado em Educação pela Universidade do Oeste Paulista - UNOESTE. ${ }^{2}$ Discente do Mestrado em \\ Educação e docente do curso de Música-Licenciatura da Universidade do Oeste Paulista - UNOESTE. ${ }^{3}$ Docente do \\ programa de Mestrado em Educação e do curso de Direito da UNOESTE. Docente da Universidade Estadual do Mato \\ Grosso do Sul (UEMS). E-mail: etomiazzi@hotmail.com
}

\section{RESUMO}

Com a promulgação da lei n.o 11.769/08, o ensino da música é conteúdo obrigatório em toda a educação básica. Não sendo uma disciplina exclusiva e não contando com um professor específico da área, o sistema de ensino busca se adequar a lei. Interpretando a referida lei, na educação infantil quando a instituição de ensino não possui um professor especialista da área, o conteúdo musical deve ser desenvolvido pelo professor licenciado em pedagogia. Contudo, percebe-se que estes professores não tem ciência do objetivo da Educação Musical no contexto escolar, nem dos conteúdos e metodologias a serem abordados para alcançar tais objetivos. Assim, este artigo analisa os Referenciais Curriculares Nacionais para a Educação Infantil buscando identificar como estes documentos definem Educação Musical na escola, apresentando seus objetivos e conteúdos, e como orientam os professores e agentes da Educação Infantil a desenvolver música com seus alunos, sugerindo metodologias.

Palavras-chave: Educação Musical, Educação Infantil, Referenciais Curriculares Nacionais para a Educação Infantil.

\section{INTRODUÇÃO E OBJETIVOS}

A música é uma linguagem, uma forma de expressão humana, e assim, um patrimônio cultural, que desde a Grécia antiga é considerada uma área importante na formação dos cidadãos. Contudo, atualmente a música encontra dificuldades de se instaurar efetivamente no contexto escolar brasileiro, por diversos motivos. Dentre eles, leis que regulamentam o ensino de Arte como área polivalente, em que o professor pedagogo ou o professor de arte são os responsáveis por desenvolver teatro, dança, artes plásticas e música. Mas, o que se presencia na escola hoje é uma prevalência das artes plásticas em relação às outras formas de expressão artística.

Em Agosto de 2008, foi sancionada a lei 11.769 que regulamenta o ensino de música na escola, tornando-o conteúdo obrigatório, mas não exclusivo. Com a obrigatoriedade e não contando com uma disciplina específica e nem com professores especialistas em música, as escolas buscam se adequar à lei.

No caso da Educação Infantil, o professor pedagogo, além das disciplinas que já desenvolve, busca promover atividades musicais com seus alunos para atender à necessidade 
curricular da escola, entretanto, pesquisas revelam que estes professores têm dificuldade em desenvolver tais atividades por não conhecerem os objetivos e conteúdos que devem ser desenvolvidos com crianças de zero a seis anos, e pouco sabem sobre como promover tal desenvolvimento. Assim, acabam usando-se da música como ferramenta pedagógica, no ensino de outras disciplinas, e acreditando que assim estão promovendo a Educação Musical prevista pela lei.

Percebe-se com esta prática dos professores que falta no contexto escolar uma clareza da real função da música na escola, bem como uma orientação de o que deve ser desenvolvido nas aulas de música e quais metodologias o professor pode seguir para atingir plenamente seus objetivos. Para auxiliá-los e orientar sua prática, o MEC propõe os Referenciais Curriculares Nacionais para a Educação Infantil (RCNEI), que apesar de não serem obrigatórios aos professores, apontam possibilidades de objetivos, conteúdos e metodologias a serem desenvolvidas nas diversas áreas, inclusive música.

Diante de tal situação, este artigo investiga e apresenta de que forma os objetivos e conteúdos musicais são propostos pelo RCNEI, e se estes são possíveis de serem desenvolvidos pelos agentes da Educação Infantil, sejam eles professores com conhecimento específico musical ou não.

\section{METODOLOGIA}

Para atingir tal objetivo, realizamos uma pesquisa documental, analisando o volume 3 do Referencial Curricular Nacional para a Educação Infantil, documento proposto pelo governo que apresenta os conhecimentos de mundo a serem desenvolvidos com crianças de zero a seis anos. Dentre os conhecimentos de mundo está a música.

A partir dos dados levantados, discutimos se as orientações presentes neste documento deixam claros os objetivos e conteúdos da Educação Musical, de forma que professores especialistas e não especialistas compreendam e tenham fundamentos para planejar suas aulas.

\section{RESULTADOS}

O Referencial Curricular Nacional para a Educação Infantil, volume 3 - Conhecimento de Mundo, apresenta os objetivos e conteúdos de música no contexto escolar, além de orientações didáticas que auxiliam a prática dos professores, para o desenvolvimento de crianças de 0 a 6 anos. De acordo com o Referencial Curricular Nacional para Educação Infantil (1998) 
A linguagem musical tem estrutura e características próprias, devendo ser considerada em três eixos: Produção - centrada na experimentação e na imitação, tendo como produtos musicais a interpretação, a improvisação e a composição; Apreciação - percepção tanto dos sons e silêncios quanto das estruturas e organizações musicais, buscando desenvolver, por meio do prazer da escuta, a capacidade de observação, análise e reconhecimento; Reflexão - sobre questões referentes à organização, criação, produtos e produtores musicais. (BRASIL, 1998, p.48).

Assim, apresentam-se os objetivos para crianças de zero a três anos: "ouvir, perceber e discriminar eventos sonoros diversos, fontes sonoras e produções musicais; brincar com a música, imitar, inventar e reproduzir criações musicais" (BRASIL, 1998, p. 55). Como objetivos para crianças de quatro a seis anos, o RCNEI (ibidem) nos averba: "explorar e identificar elementos da música para se expressar, interagir com os outros e ampliar seu conhecimento do mundo; perceber e expressar sensações, sentimentos e pensamentos, por meio de improvisações, composições e interpretações musicais."

Segundo o RCNEI, o processo de desenvolvimento musical deve abranger:

a exploração de materiais e a escuta de obras musicais para propiciar o contato e experiências com a matéria-prima da linguagem musical: o som (e suas qualidades) e o silêncio; a vivência da organização dos sons e silêncios em linguagem musical pelo fazer e pelo contato com obras diversas; a reflexão sobre a música como produto cultural do ser humano é importante forma de conhecer e representar o mundo. (BRASIL, 1998, p. $57)$.

Como bases nisso, os conteúdos musicais são organizados pelo RCNEl em dois blocos: 0 "fazer musical" e a "Apreciação musical", sendo que, ambos abarcam questões e discussões alusivas no que tange à reflexão.

Conforme aponta Brito (2003, p.57), "consideramos fazer musical como o contato entre a realização acústica de um enunciado musical e seu receptor, seja este alguém que cante, componha, dance ou simplesmente ouça". Noutras palavras, o "fazer musical" é uma maneira de se comunicar e de se expressar por meio da improvisação, da composição e da interpretação. 0 "improviso" acontece em torno da criação sobre algo já realizado. O RCNEI apresentam como orientação didática jogos e brincadeiras de improviso, que proporcionam excelente estímulo musical na educação infantil, pois possibilita exercícios criativos favorecendo o desenvolvimento da comunicação e da expressão. O contato com a "composição" ocorre a partir de estruturas fixas da linguagem musical, também de grande valia para o percurso da educação musical no contexto 
escolar infantil. E o ato de "interpretar" é promovido pela execução de uma composição musical pela participação como intérprete. Segundo o RCNEI (1998, p. 57), a imitação é à base do trabalho de interpretação. Imitando sons vocais, corporais, ou produzidos por instrumentos musicais, as crianças preparam-se para interpretar quando, então, imitam expressivamente.

Sendo assim, o conteúdo musical para o "fazer musical", com crianças de zero a três anos, é disposto no Referencial pela: "exploração, expressão e produção do silêncio e de sons com a voz, o corpo, o entorno e materiais sonoros diversos; interpretação de músicas e canções diversas; participação em brincadeiras e jogos cantados e rítmicos". (BRASIL, p. 58).

Como orientação didática para desenvolver o "fazer musical" com crianças desta faixa etária, o Referencial orienta que

No primeiro ano de vida, a prática musical poderá ocorrer por meio de atividades lúdicas. O professor estará contribuindo para o desenvolvimento da percepção e atenção dos bebês quando canta para eles; produz sons vocais diversos por meio da imitação de vozes de animais, ruídos etc., ou sons corporais, como palmas, batidas nas pernas, pés etc.; embala-os e dança com eles. As canções de ninar tradicionais, os brinquedos cantados e rítmicos, as rodas e cirandas, os jogos com movimentos, as brincadeiras com palmas e gestos sonoros corporais, assim como outras produções do acervo cultural infantil, podem estar presentes e devem se constituir em conteúdos de trabalho. Isso pode favorecer a interação e resposta dos bebês, seja por meio da imitação e criação vocal, do gesto corporal, ou da exploração sensório-motora de materiais sonoros, como objetos do cotidiano, brinquedos sonoros, instrumentos musicais de percussão como chocalhos, guizos, blocos, sinos, tambores etc. (BRASIL 1998, p. 58).

$\mathrm{Na}$ fase entre quatro a seis anos, a criança amplia seus conhecimentos e possibilidades de trabalho no fazer musical, tendo visto que já vinham sendo desenvolvidas com as crianças de zero a três. (BRASIL, 1998). A reflexão, um dos três eixos propostos pelo RCNEI, relaciona-se com os aspectos referentes aos conteúdos da linguagem musical para esta etapa.

Reconhecimento e utilização expressiva, em contextos musicais das diferentes características geradas pelo silêncio e pelos sons: altura (graves ou agudos), duração (curtos ou longos), intensidade (fracos ou fortes) e timbre (característica que distingue e "personaliza" cada som). Reconhecimento e utilização das variações de velocidade e densidade na organização e realização de algumas produções musicais. Participação em jogos e brincadeiras que envolvam a dança e/ou a improvisação musical. Repertório de canções para desenvolver memória musical. (BRASIL 1998, p. 59).

No que tange a apreciação musical, o RCNEI nos traz a seguinte denominação: "A apreciação musical refere-se à audição e interação com músicas diversas". (BRASIL 1998, p. 63). 
O educador musical inglês Keith Swanwick (2003) apresenta a ideia de que o objetivo primário da educação musical é desenvolver uma apreciação musical rica e ampla, porque esta oferece prazer imediato, contribuindo ao mundo dos sentimentos proporcionando sentido à vida. Swanwick menciona ainda que os educadores musicais devem levar o aluno ao aprendizado da apreciação para propiciar o desenvolvimento da capacidade imaginativa.

Por esta via, conferimos na Figura 1 abaixo os conteúdos referentes à apreciação musical para crianças de zero a três anos e de quatro a seis anos, segundo o RCNEI.

\section{CRIANÇAS DE QUATRo A SEIS ANOS}

\section{CRIANÇAS DE ZERO E TRÊS ANOS}

- Escuta de obras musicais variadas.

- Participação em situações que integrem músicas, canções e movimentos corporais.

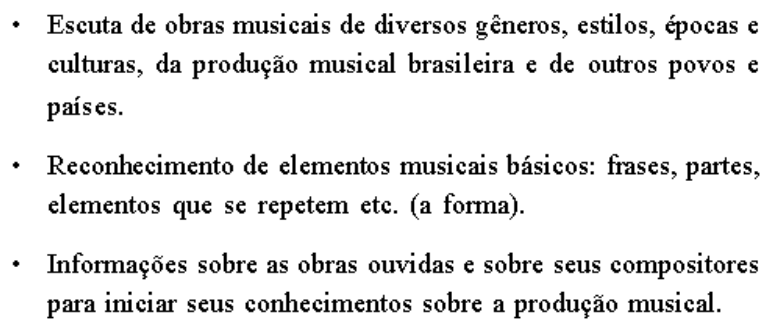
para iniciar seus conhecimentos sobre a produção musical.

Figura 1. Conteúdos musicais sugeridos a crianças de zero a três anos.

Fonte: RCNEI - p.63-64.

A partir disto, para crianças de zero a três anos, o referencial destaca que "o trabalho com a apreciação musical deverá apresentar obras que despertem o desejo de ouvir e interagir, pois para essas crianças ouvir é, também, movimentar-se, já que as crianças percebem e expressam-se globalmente". (BRASIL 1998, p.64).

Neste mesmo aspecto da apreciação musical, para as crianças de quatro a seis anos o RCNEI propõe que:

Nessa faixa etária, o trabalho com a audição poderá ser mais detalhado, acompanhando a ampliação da capacidade de atenção e concentração das crianças. A apreciação musical poderá propiciar o enriquecimento e ampliação do conhecimento de diversos aspectos referentes à produção musical: os instrumentos utilizados; tipo de profissionais que atuam e o conjunto que formam (orquestra, banda etc.); gêneros musicais; estilos etc. O contato com uma obra musical pode ser complementado com algumas informações relativas ao contexto histórico de sua criação, a época, seu compositor, intérpretes etc. (BRASIL 1998, p.65). 


\section{DISCUSSÃO}

Os objetivos e conteúdos propostos pelo RCNEI abordam possibilidades de uma aprendizagem significativa no que se refere ao desenvolvimento, a comunicação e a expressão por meio da linguagem musical. Essas possibilidades estão imersas nos processos de aprendizagem do educando, que está em constante desenvolvimento.

Ouvir uma música, saber distinguir e discriminar os sons que a contém; diferenciar as propriedades sonoras e inseri-las no dia a dia; cantar uma melodia, mesmo que seja simples; dançar conforme um estilo musical; introduzir o som e o silêncio em brincadeiras infantis; sonorizar histórias com sons musicais e/ou ruídos; observar e identificar os sons do cotidiano (sons de animais, sons da natureza, sons do meio de transporte), que fazem parte de nossa paisagem sonora ${ }^{1}$, são conteúdos básicos e elementares para uma atividade musical por excelência na educação infantil.

Esses conteúdos bem executados despertam ao educando um percurso estruturado e orientado no desenvolvimento para uma escuta sensível, enriquecendo sua memória musical transformando sua experiência musical ativa, reflexiva e significativa.

Tais objetivos e conteúdos propostos por este documentos são possíveis de serem desenvolvidos na Educação Infantil. À vista disso, Jeandot (1997) assevera que a criança de dois é capaz de:

Cantar versos soltos, fragmentos de canções, geralmente fora do tom. Reconhece algumas melodias e cantores. Gosta de movimentos rítmicos em rede, cadeira de balanço, etc. A criança de três anos consegue reproduzir canções inteiras. Embora geralmente fora do tom. Tem menos inibição para cantar em grupo. Reconhece várias melodias. Começa a fazer coincidir os tons simples de seu canto com as músicas ouvidas. Tenta tocar instrumentos musicais. Gosta de participar de grupos rítmicos: marcha, pula, caminha, corre, seguindo o compasso da música. (JEANDOT 1997, p. 63).

Vale mencionar que o canto desenvolve um papel fundamental na educação infantil. A voz é um instrumento musical natural, e por ser frequentemente usado pelas crianças e professores para o diálogo e a comunicação, integra um papel muito importante na oralidade.

Além disso, o desenvolvimento musical da criança se permeia na melodia e no ritmo ${ }^{2}$, que, por intermédio dessa linguagem o educando possa usufruir da experiência em ouvir, imitar,

\footnotetext{
1 Paisagem sonora. "Soundscape". Termo criado pelo músico e educador canadense Murray Schafer para designar todos os sons que nos acompanham diariamente.

${ }^{2}$ Melodia e ritmo. Elementos estruturais e expressivos da música.
} 
cantar, tocar objetos sonoros e interpretar músicas do cancioneiro popular infantil bem como da música popular brasileira, assim, compreendendo e comunicando-se por meio da música.

Acerca das habilidades musicais que podem ser desenvolvidas com crianças de quatro a seis anos, Jeandot (1997) averba que aos

4 anos, a criança progride no controle da voz. Participa com facilidade de jogos simples, cantados. Interessa-se muito em dramatizar as canções. Cria pequenas músicas durante a brincadeira; 5 anos, a criança entoa mais facilmente e consegue cantar melodias inteiras.[...] Consegue sincronizar os movimentos da mão ou do pé com a música.[...] Consegue pular em um só pé e dançar conforme o ritmo da música. Percebe a diferença dos diversos timbres (vozes, objetos, instrumentos), dos sons graves e agudos, além da variação de intensidade (forte e fraca); 6 anos, a criança percebe sons ascendentes e descendentes. Identifica as fórmulas rítmicas, os fraseados musicais, as variações de andamento e a duração dos valores sonoros. Adapta palavras sobre ritmos ou trecho musical já conhecido. Acompanha e repete uma sequência rítmica. (JEANDOT 1997, p. 63-64).

Sendo assim, Brito (2003) apresenta a importância de como a linguagem musical deve ser contemplada no dia a dia das creches e pré-escolas pelas atividades de:

Trabalho vocal; interpretação e criação de canções; brinquedos cantados e rítmicos; jogos que reúnem som, movimento e dança; jogos de improvisação; sonorização de histórias; elaboração e execução de arranjos (vocais e instrumentais); invenções musicais (vocais e instrumentais); construção de instrumentos e objetos sonoros; registro e notação; escuta sonora e musical: escuta atenta, apreciação musical; reflexões sobre a produção e a escuta. (BRITO 2003, p. 58).

É de grande valia ressaltar que, o professor mesmo não sendo especialista da área de música, pode contribuir para o enriquecimento da apreciação musical dos seus alunos proporcionando-Ihes atividades significativas ao uso da linguagem musical como exemplo, associar imagens de instrumentos musicais ao som produzidos pelo mesmo através de Cd's ou DVD's; mostrando e nomeando por meio de livros ou algo do gênero grandes intérpretes e compositores da música universal e da música tradicional brasileira, além das composições contemporâneas e populares regionais, sempre permitindo o acesso aos educando e deixando-os guiar-se pela sensibilidade, pela sensação e pela motivação que a música propicia.

Por esta premissa, o professor, mesmo não sendo especialista da área, pode ser o mediador do conhecimento da linguagem musical para com seus alunos por meio de atividades lúdicas contribuindo com o desenvolvimento da percepção auditiva, dos jogos com movimentos (dança) e acesso ao acervo cultural infantil por cantigas tradicionais de nosso cancioneiro popular. 
Porém, Fonterrada (2008) vem corroborar de modo a analisar de como a linguagem musical deve ser aplicada em creches e pré-escolas de nosso país, e critica a ausência de uma orientação no RCNEI de como realizar a integração das quatro expressões artísticas, uma vez que tais modalidades devem ser desenvolvidas por um único professor (polivalente).

[...] a principal tarefa do professor da creche ou da escola de educação infantil é lidar, de modo vivo e integrado, com todas as atividades, conteúdos e ações. Isso, porém, está ausente no documento, e a integração tem de ser feita pelo próprio professor. É bom que o professor imagine, ele mesmo, maneiras de fazer a integração, pois isso o leva a refletir acerca da própria experiência. No entanto, nas condições atuais em que as escolas e creches vivem, esse tipo de conduta é inadequada, pois não há garantia de que a reflexão seja feita por cada professor ou mesmo pela instituição. A capacidade de refletir acerca da própria prática é um ideal a ser perseguido, mas no momento, difícil de ser realizado. (FONTERRADA 2008, p. 261).

Mesmo assim, Fonterrada (2008, p. 261) elucida que é possível que o professor polivalente desenvolva música no contexto infantil, ao dizer: "[...] Para que os objetivos sejam atingidos, é preciso que haja suporte, supervisão e cursos de capacitação e aperfeiçoamento docente".

Conquanto, mesmo que o professor encontre dificuldades na realização da linguagem musical no ambiente escolar, como é proposto pelo RCNEI, é fidedigno dizermos que o mesmo busque orientações a fim de utilizar-se com autonomia e suscetibilidade acerca da música na educação infantil.

\section{CONCLUSÃO}

Conclui-se que o RCNEI orienta sobre os reais objetivos e conteúdos da linguagem musical, e propõe metodologias significativas para viabilizar a prática dos professores da Educação Infantil, mesmo não sendo especialistas de área. Contudo, há práticas musicais que para sua realização, o docente necessita de domínio da linguagem musical.

Compreendemos que a música é uma forma de linguagem e de conhecimento, estando em constante presença no dia a dia das crianças de modo acentuado: na TV, no rádio, e em diversas situações como brincadeiras e brincos infantis, além de outras de convívio social. Este conhecimento para o professor, pode ser fortalecido por meio de formação continuada específica em música. Desta forma, o desenvolvimento musical no contexto escolar não se restringe ao uso da música como ferramenta para o ensino de outras áreas, passando a ser compreendida como um conhecimento importante na formação integral da criança. 


\section{REFERÊNCIAS}

BRASIL. Ministério da Educação e do Desporto. Secretaria de Educação Fundamental. Referencial curricular nacional para a educação infantil / Ministério da Educação e do Desporto, Secretaria de Educação Fundamental. - Brasília: MEC/SEF, 1998. 3v.: il.

BRITO, Teca Alencar de. Música na Educação Infantil. Propostas para a formação integral da criança. São Paulo: Peirópolis, 2003.

FONTERRADA, M. T. de O. De tramas e fios: um ensaio sobre música e educação. 2. ed. - São Paulo: Editora UNESP; Rio de Janeiro: Funarte, 2008.

JEANDOT, Nicole. Explorando o Universo da Música. São Paulo: Scipione, 1997.

SCHAFER, Murray. O Ouvido Pensante. São Paulo: Editora Unesp, 1991.

SWANWICK, Keith. Ensinando Música Musicalmente. São Paulo: Moderna, 2003. 